\title{
Adverse neonatal effects of maternal labetalol treatment
}

\author{
B N A Crooks, S A Deshpande, C Hall, M P Ward Platt, D W A Milligan
}

\begin{abstract}
Two infants with features of severe $\beta$ adrenergic blockade, pericardial effusions, and myocardial hypertrophy were born to mothers receiving long term treatment with oral labetalol for hypertension in pregnancy. Labetalol was implicated in the aetiology of these problems. Pericardial effusion and myocardial hypertrophy have not been associated with labetalol toxicity in neonates.

(Arch Dis Child Fetal Neonatal Ed 1998;79:F150-F151)
\end{abstract}

Keywords: labetalol; hypotension; hypoglycaemia

Labetalol, a non- selective $\beta$ and $\alpha_{1}$ antagonist, is commonly used to treat hypertension during pregnancy. Through $\alpha_{1}$ adrenoceptor blockade, it causes peripheral vasodilatation while $\beta$ blockade prevents reflex tachycardia and maintains cardiac output. We report two infants with features of severe $\beta$ blockade, cardiac ventricular hypertrophy, and pericardial effusions whose mothers had received long term oral labetalol treatment.

\section{Case reports}

CASE 1

A 30 year old primigravid woman with essential hypertension was treated with labetalol $(800 \mathrm{mg} /$ day) from 8 weeks of pregnancy, and atenolol ( $50 \mathrm{mg} /$ day) at 20 weeks in view of poor control. Serial ultrasound scans had shown symmetric growth retardation and an isolated pericardial effusion. Latterly reversed end diastolic umbilical arterial flow precipitated delivery of a girl weighing $1010 \mathrm{~g}$ at 30 weeks. Cord blood $\mathrm{pH}$ and base excess were 7.03 and $-12.9 \mathrm{mmol} / 1$, respectively, and the baby required ventilation for resuscitation.

The baby was mechanically ventilated from

Newcastle Neonatal Service Special Care Baby Unit,

Royal Victoria

Infirmary,

Newcastle upon Tyne B Crooks

S Deshpande

$M$ Ward Platt

D Milligan

Department of

Pharmacy

C Hall

Correspondence to: Dr S A Deshpande Neonatal Unit, Royal Shrewsbury Hospitals NHS Trust, Mytton Oak Road, Shrewsbury SY3 8XQ.

Accepted 2 February 1998 was hypoten fusion. By 20 hours of age, she was bradycardic, hypotensive (mean arterial blood pressure 20 to $25 \mathrm{~mm} \mathrm{Hg}$ ), and poorly perfused. A chest $x$-ray picture showed a large globular heart. An echocardiogram showed normal cardiac anatomy, a moderate pericardial effusion, and marked concentric hypertrophy of the left ventricle. She was treated with volume expansion and inotropes (dopamine and dobutamine) until day 5. Echocardiography showed gradual resolution of the pericardial effusion by day 10 and of the ventricular hypertrophy by day 43 .

Persistent hypoglycaemia from 6 hours of age required between 10.4 to $13.3 \mathrm{mg} / \mathrm{kg}$ per minute of glucose for control. Her hypoglycae- mia settled by day 6 . She made a full recovery and was discharged home by 2 months of age.

CASE 2

A 35 year old primigravid woman was treated with labetalol ( $800 \mathrm{mg} /$ day) and nifedipine (30 $\mathrm{mg}$ /day) for severe pregnancy induced hypertension from 30 weeks onwards. Five weeks later, a boy weighing $2250 \mathrm{~g}$ was delivered by caesarean section because of fetal bradycardia. The baby was resuscitated with face mask ventilation, establishing regular respirations by 4 minutes of age. Arterial blood $\mathrm{pH}$ and base excess at 20 minutes of age were 6.97 and -8.5 $\mathrm{mmol} / \mathrm{l}$, respectively. The infant became apnoeic and cyanosed at 20 minutes of age and was therefore ventilated and transferred to our unit. He was bradycardic (heart rate around 98/minute), hypotensive (mean blood pressure between 23 and $34 \mathrm{~mm} \mathrm{Hg}$ ), and hypoglycaemic (blood glucose $<0.5 \mathrm{mmol} / \mathrm{l}$ ). A chest $x$-ray picture showed cardiomegaly with hazy lung fields while an echocardiogram revealed a small pericardial effusion, biventricular hypertrophy, poor myocardial contractility, tricuspid regurgitation and bidirectional flow through patent oval foramen and arterial duct. In view of the features suggestive of $\beta$ blockade, the infant was treated with intramuscular glucagon (250 $\mu \mathrm{g})$, resulting in a rise in blood pressure and blood glucose concentration. His hypotension and hypoglycaemia recurred, however, and needed inotropic support with dobutamine, dopamine, and noradrenaline. Recurrence of hypoglycaemia required glucose infusion of 10 $\mathrm{mg} / \mathrm{kg}$ per minute and repeated doses of glucagon.

The infant also showed features of severe hypoxic-ischaemic encephalopathy, and died on day 6. The necropsy showed features of severe hypoxic-ischaemic brain injury, hyaline membrane disease, and biventricular cardiac hypertrophy.

\section{Discussion}

Both these infants had pericardial effusions and concentric ventricular hypertrophy, in addition to features such as bradycardia, persistent hypotension, and hypoglycaemia. The latter may occur as a result of fetal growth retardation or hypoxic injury, but they also have been ascribed to neonatal $\beta$ adrenergic blockade from maternal labetalol treatment, especially in preterm $^{1-3}$ and asphyxiated neonates. ${ }^{4}$ Although labetalol is considered generally safe in term neonates, ${ }^{5}$ decreased urinary disposal and lower albumin binding in preterm infants may prolong its half life and increase its bioavailability and toxicity. ${ }^{6}$ It has 
been suggested that labetalol may interfere with catecholamine mediated circulatory responses and this may be particularly deleterious in acidotic asphyxiated infants. ${ }^{7}$ Although we did not measure the plasma and urinary concentrations of labetalol, we believe that the features of adrenergic blockade may implicate labetalol as a possible causative factor in the pericardial effusions and myocardial hypertrophy noted in our infants. Although short term labetalol infusion does not impair cardiac function and peripheral vascular resistance, ${ }^{8}$ prolonged $\alpha$ and $\beta$ adrenergic blockade might have been responsible for the myocardial hypertrophy in our infants. The resolution of the ventricular hypertrophy in case 1 over the first 6 weeks after birth supports this hypothesis.

Glucagon, which increases intracellular concentration of cyclic adenosine monophosphate through direct stimulation of the calcium dependent channel, is an antidote for labetalol toxicity. In case 2 hypoglycaemia was abolished and blood pressure rose after the administration of glucagon. That these improvements were not sustained may have been due to inad- equate dose; intravenous doses of 300-600 $\mu \mathrm{g} / \mathrm{kg}$ were needed to maintain these improvements in a recent report. ${ }^{3}$

We suggest that prolonged maternal labetalol treatment may be associated with development of myocardial hypertrophy and pericardial effusions in neonates, and that treatment with intravenous glucagon be considered in such infants if they have features of $\beta$ blockade.

1 Haraldsson A, Geven W. Severe adverse effects of maternal labetalol in a premature infant. Acta Pediatr Scand 1989;78:956-8.

2 Klarr JM, Bhatt-Mehta V, Donn SM. Neonatal adrenergic blockade following a single dose maternal labetalol administration. Am f Perinatol 1994;11:91-3.

3 Stevens TP, Guillet R. Use of glucagon to treat neonatal low-output congestive heart failure after maternal labetalo therapy. F Pediatr 1995;127:151-3.

4 Olsen KS, Beier-Holmersen R. Fetal death following labetalol administration in preeclampsia. Acta Obstet Gynecol 1992;71:145-7.

5 Macpherson M, Broughton Pipkin F, Rutter N. The effect of maternal labetalol on the newborn infant. Br f Obstet of maternal labetalol on

6 Haraldsson A, Geven W. Half-life of maternal labetalol in a premature infant. Pharmaceutisch Weekblad 1989;11:22931 .

7 Woods DL, Malan AF. Side effects of labetalol in newborn infants. Br F Obstet Gynecol 1983;90:876.

8 Jouppila P, Rasanen J. Effect of labetalol infusion on uterine Obstet Gynecol Reprod Biol 1993;51:111-7. 